\title{
Effect of Slag Cement on Drying Shrinkage of Concrete
}

\author{
by Jiqiu Yuan, Will Lindquist, David Darwin, and JoAnn Browning
}

\begin{abstract}
The effect of a partial replacement of cement with slag cement on free shrinkage is evaluated for curing periods between 3 and 28 days. Mixtures include concrete containing different replacement levels of slag cement (30, 60, and $80 \%$ by volume) cast with limestone, granite, or quartzite coarse aggregate. Comparisons are only made with mixtures having the same paste content (by volume) and water-cementitious material ratio. The study shows that a partial replacement of cement with slag cement decreases free shrinkage compared to mixtures containing 100\% portland cement; the reduction is greatest at early ages and is improved as the replacement level is increased. Increasing the curing period decreases free shrinkage for mixtures with and without slag cement. When slag cement is used in conjunction with a porous limestone coarse aggregate, where internal curing is provided by the water stored in the pores of limestone, an even greater reduction in free shrinkage is observed compared to mixtures cast with lowabsorption coarse aggregate.
\end{abstract}

Keywords: bridge decks; cracking; curing; dry free shrinkage; internal curing; slag cement.

\section{INTRODUCTION}

Drying shrinkage of concrete is a principal cause for bridge deck cracking and subsequent deterioration. Several factors influence concrete shrinkage including the mixture design, environmental conditions, and construction procedures. This paper describes a study to determine the effect of slag cement on drying shrinkage of concrete. This study is part of a larger research program at the University of Kansas to develop low-cracking high-performance concrete (LC-HPC) for use in bridge decks. Full details of the program are provided by Darwin et al. (2004, 2010), Lindquist et al. (2006, 2008), McLeod et al. (2009), and Yuan et al. (2011).

Previous studies have compared the shrinkage of concrete containing slag cement with concrete containing only portland cement, although the results have not always been consistent. Fulton (1974) and Hogan and Meusel (1981) found that the incorporation of slag cement in concrete resulted in increased free shrinkage, while Klieger and Isberner (1967) and Brooks et al. (1992) reported that concrete containing slag cement had similar shrinkage to concrete containing only portland cement. Tazawa et al. (1989) concluded that drying shrinkage of slag cement concrete was less than that of $100 \%$ portland cement concrete when the concrete was cured for 28 days; when slag mortar was compared with $100 \%$ cement mortar, the slag mortar still had less drying shrinkage than the $100 \%$ cement mortar when they were cured for 28 days, but more shrinkage when were cured for 3 or 7 days. It is important to note that these comparisons were based on research in which slag cement was substituted on an equal-weight basis because, when substituted on an equal-weight basis, the lower specific gravity of slag cement (compared to portland cement) results in a higher paste volume that leads to higher free shrinkage. Deshpande et al. (2007) evaluated concrete containing a $30 \%$ volume replacement of portland cement with slag cement while keeping the water content constant. This resulted in increasing the water-cementitious material ratio $(w / \mathrm{cm})$ from 0.45 for the mixture containing only portland cement to 0.47 for the mixture containing slag cement. Under these conditions, Deshpande et al. (2007) found that slag cement slightly increased early-age shrinkage (through 30 days), although the ultimate shrinkage (through 1 year) was little affected. Hooton et al. (2009) summarized free shrinkage data for concrete containing slag cement from 21 studies and concluded that the drying shrinkage of concrete containing slag cement, independent of the slag cement content, was approximately the same as similar concrete without slag cement. When the data were corrected to compare the mixtures on an equal paste content basis, Hooton et al. (2009) found that the concrete containing slag cement shrank about 3\% less than concrete containing only portland cement.

This study evaluates two types of slag cement (Grade 100 and Grade 120) with varying volume replacement levels (0, 30,60 , and $80 \%$ ) in combination with different coarse aggregates (a high-absorption limestone and two low-absorption aggregates: granite and quartzite). Drying shrinkage of the paste is restrained by the aggregates, and thus the volume fraction of the aggregate plays an important role in controlling concrete shrinkage. The mixtures in each series in this study were designed to have the same volume of paste, and thus the same aggregate volume, while keeping the $w / \mathrm{cm}$ constant. Full details of the study are presented by Lindquist et al. (2008) and Yuan et al. (2011).

\section{RESEARCH SIGNIFICANCE}

Previous research has investigated the shrinkage of concrete containing slag cement. In these earlier studies, comparisons were made between mixtures that did not have the same paste content, and perhaps as a result, the effects of incorporating slag cement have not always been consistent. In contrast, the comparisons in this study involve mixtures containing an equal volume of paste in addition to having the same $w / \mathrm{cm}$. The results of this study indicate that a partial

ACI Materials Journal, V. 112, No. 2, March-April 2015.

MS No. M-2013-264.R2, doi: 10.14359/51687129, received February 20, 2014, and reviewed under Institute publication policies. Copyright (C) 2015, American Concrete Institute. All rights reserved, including the making of copies unless permission is obtained from the copyright proprietors. Pertinent discussion including author's closure, if any, will be published ten months from this journal's date if the discussion is received within four months of the paper's print publication. 
replacement of portland cement with slag cement reduces drying shrinkage and that lengthening the curing period or providing internal curing increases this reduction. The combination of these strategies provides an approach that can be used to limit cracking resulting from restrained shrinkage.

\section{Materials}

\section{EXPERIMENTAL INVESTIGATION}

All of the concrete in this study contained Type I/II cement. Limestone (with an absorption between 2.5 and $3.1 \%$ ), granite (with an absorption between 0.6 and $0.8 \%$ ), and quartzite (with an absorption of $0.4 \%$ ) were used as coarse aggregates. The fine aggregate consisted of river-run sand and pea gravel. Both Grade 120 and Grade 100 slag cements (ASTM C989/C989M 2012) were evaluated. Two samples of Grade 120 slag cement, designated as samples (I) and (II), and three samples of Grade 100 slag cement, designated as samples (i), (ii), and (iii), were used. The chemical composition of the slag cements is presented in Table 1. A polycarboxylate-based high-range water reducing admixture and a tall oil (liquid rosin)-based air-entraining agent were used to obtain the desired slump and air content.

\section{Concrete mixtures}

The concretes in this study were designed for potential use as low-cracking mixtures, and thus, all had low paste contents and optimized aggregate gradations (Lindquist et al. 2008; Yuan et al. 2011). Three programs were included in the study: Grade 120 and 100 slag cements were evaluated in Programs I and II, respectively, while the effect of internal curing on mixtures containing slag cement was studied in Program III. The mixture proportions are summarized in Table 2. A control mixture containing $100 \%$ portland cement (cast with cement from the same sample) is included in each set.

Program I included mixtures containing Grade 120 slag cement cast with either limestone or granite coarse aggregate. In the first set of Program I, mixtures containing 30 and $60 \%$ volume replacements of cement with slag cement (I) and mixtures containing 60 and $80 \%$ volume replacements of cement with slag cement (II) were compared with a mixture containing 100\% cement. All mixtures in Program I Set 1 were cast with the relatively porous limestone coarse aggregate, which provided internal curing, had a $w / \mathrm{cm}$ of 0.42 , and a paste content of $23.3 \%$ (by volume), and were cured for 7 or 14 days prior to drying. The second set contained granite coarse aggregate with a $60 \%$ volume replacement of cement with slag cement (II). All mixtures in Program I Set $2 \mathrm{had}$ a $w / \mathrm{cm}$ of 0.44 and a paste content of $24.1 \%$, and were cured for $3,7,14$, or 28 days.

Grade 100 slag cement was evaluated in Program II. Program II also included mixtures containing different replacement levels of slag cement cast with either limestone or granite coarse aggregate. In Program II Set 1, replacements of 0,30 , and $60 \%$ by volume of cement with slag cement (i) were evaluated and all mixtures had limestone coarse aggregate, a $w / \mathrm{cm}$ of 0.42 , and a paste content of $23.3 \%$. In the second set, replacements of 0,30 , and $60 \%$, by volume of cement with slag cement (ii) were evaluated again but with granite coarse aggregate. The mixtures in
Table 1-Chemical composition of slag cements, $\%$

\begin{tabular}{|c|c|c|c|c|c|}
\hline \multirow[b]{3}{*}{ Oxides } & \multicolumn{5}{|c|}{ Mineral admixture } \\
\hline & \multicolumn{2}{|c|}{ Grade 120 slag cement } & \multicolumn{3}{|c|}{ Grade 100 slag cement } \\
\hline & I & II & $i^{*}$ & ii & iii \\
\hline $\mathrm{SiO}_{2}$ & 32.70 & 38.28 & - & 43.36 & 36.35 \\
\hline $\mathrm{Al}_{2} \mathrm{O}_{3}$ & 8.58 & 10.69 & - & 8.61 & 9.64 \\
\hline $\mathrm{Fe}_{2} \mathrm{O}_{3}$ & 1.70 & 0.49 & - & 0.37 & 0.88 \\
\hline $\mathrm{CaO}$ & 44.82 & 35.35 & - & 31.13 & 39.92 \\
\hline $\mathrm{MgO}$ & 9.33 & 10.68 & - & 12.50 & 9.17 \\
\hline $\mathrm{SO}_{3}$ & 1.16 & 2.85 & - & 2.24 & 2.21 \\
\hline $\mathrm{Na}_{2} \mathrm{O}$ & 0.30 & 0.27 & - & 0.21 & 0.23 \\
\hline $\mathrm{K}_{2} \mathrm{O}$ & 0.41 & 0.37 & - & 0.40 & 0.44 \\
\hline $\mathrm{TiO}_{2}$ & 0.57 & 0.44 & - & 0.32 & 0.50 \\
\hline $\mathrm{P}_{2} \mathrm{O}_{5}$ & 0.06 & 0.01 & - & - & 0.02 \\
\hline $\mathrm{Mn}_{2} \mathrm{O}_{3}$ & 0.45 & 0.34 & - & 0.35 & 0.40 \\
\hline $\mathrm{SrO}$ & 0.09 & 0.05 & - & 0.04 & 0.07 \\
\hline $\mathrm{BaO}$ & - & - & - & - & - \\
\hline LOI & 0.00 & 0.00 & - & 0.37 & 0.00 \\
\hline Total & 100.17 & 99.82 & - & 99.90 & 99.83 \\
\hline
\end{tabular}

${ }^{*}$ Chemical composition of the first Grade 100 slag cement sample was not analyzed.

Program II Set 2 had a $w / \mathrm{cm}$ of 0.44 and a paste content of $24.1 \%$ (by volume). The concrete in both sets was cured for 7 or 14 days.

In Program III, the effect of incorporating a porous limestone coarse aggregate with slag cement was investigated using comparisons with slag mixtures cast with granite (Set 1) and quartzite (Set 2) coarse aggregates. All mixtures contained a $60 \%$ volume replacement of cement with slag cement, a $w / \mathrm{cm}$ of 0.42 , and a paste content of $23.3 \%$. A mixture containing $100 \%$ cement and limestone coarse aggregate was also included in Program III Set 1. The concrete in Set 1 was cured for 14 days and the concrete in Set 2 was cured for 7 or 14 days.

The mixtures that were compared in each set had the same $w / \mathrm{cm}$ and paste content, although the $w / \mathrm{cm}$ and paste content differed for mixtures in different programs/sets. The changes reflected changes made in mixtures that were being used for low-cracking, high-performance bridge deck construction in Kansas at the time these laboratory mixtures were cast (Lindquist et al. 2008; Yuan et al. 2011). All mixtures in this study were cast with a slump of $3 \pm 1$ in. $(75 \pm 25 \mathrm{~mm})$ and an air content of $8.4 \pm 0.5 \%$ at a concrete temperature of $70^{\circ} \pm 3^{\circ} \mathrm{F}\left(21.1^{\circ} \pm 1.7^{\circ} \mathrm{C}\right)$ to minimize the influence of these parameters on shrinkage.

\section{Free shrinkage and compressive strength tests}

The free shrinkage tests were performed in accordance with ASTM C157/C157M (2008). Three test specimens with dimensions of $3 \times 3 \times 11-1 / 4$ in. $(76 \times 76 \times 286 \mathrm{~mm})$ were cast for each test condition, and the average results of the three specimens are reported. Free shrinkage measurements were taken using a mechanical dial gauge length comparator. Initial readings were taken when the specimens were 
Table 2-Concrete mixture proportions, $\mathrm{Ib} / \mathrm{yd}^{3}$

\begin{tabular}{|c|c|c|c|c|c|c|c|c|c|}
\hline Set $^{*}$ & Mixtures & Cement & Slag & $w / \mathrm{cm}$ & $\begin{array}{c}\text { Paste } \\
\text { content, } \%{ }^{\dagger}\end{array}$ & $\begin{array}{c}\text { Coarse } \\
\text { aggregate }\end{array}$ & Pea gravel & Sand & Curing period, $\mathrm{d}$ \\
\hline \multicolumn{10}{|c|}{ Program I (Grade 120 slag) } \\
\hline \multirow{3}{*}{1} & $30 \%$ slag $\left(I^{\dagger}\right)$, LS & 381 & 148 & 0.42 & 23.3 & 1400 & 780 & 829 & 7,14 \\
\hline & $60 \%$ slag $\left(I^{\ddagger}\right)$, LS & 221 & 301 & 0.42 & 23.3 & 1362 & 834 & 814 & 7,14 \\
\hline & $80 \%$ slag $\left(\mathrm{II}^{\ddagger}\right), \mathrm{LS}$ & 112 & 405 & 0.42 & 23.3 & 1537 & 718 & 752 & 7,14 \\
\hline \multirow{2}{*}{2} & $100 \%$ cement, $\mathrm{G}$ & 540 & - & 0.44 & 24.1 & 1454 & 723 & 806 & $3,7,14,28$ \\
\hline & $60 \%$ slag $\left(\mathrm{II}^{\ddagger}\right), \mathrm{G}$ & 223 & 304 & 0.44 & 24.1 & 1372 & 779 & 837 & $3,7,14,28$ \\
\hline \multicolumn{10}{|c|}{ Program II (Grade 100 slag) } \\
\hline \multirow{3}{*}{2} & $100 \%$ cement, $\mathrm{G}$ & 535 & - & 0.42 & 23.3 & 1360 & 937 & 747 & 7,14 \\
\hline & $30 \%$ slag $\left(\mathrm{ii}^{\S}\right), \mathrm{G}$ & 381 & 147 & 0.42 & 23.3 & 1416 & 853 & 773 & 7,14 \\
\hline & $60 \%$ slag $\left(\mathrm{ii}^{\S}\right), \mathrm{G}$ & 222 & 298 & 0.42 & 23.3 & 1416 & 854 & 882 & 7,14 \\
\hline \multicolumn{10}{|c|}{ Program III } \\
\hline \multirow{3}{*}{1} & $100 \%$ cement, LS & 535 & - & 0.42 & 23.3 & 1391 & 1164 & 454 & 14 \\
\hline & $60 \%$ slag $\left(\mathrm{iii}^{\S}\right)$, LS & 222 & 298 & 0.42 & 23.3 & 1357 & 1013 & 666 & 14 \\
\hline & $60 \%$ slag $\left(\mathrm{iiii}^{\S}\right), \mathrm{G}$ & 222 & 298 & 0.42 & 23.3 & 1384 & 1180 & 444 & 14 \\
\hline 2 & $60 \%$ slag $\left(\mathrm{II}^{\ddagger}\right), \mathrm{LS}$ & 221 & 301 & 0.42 & 23.3 & 1537 & 718 & 752 & 7,14 \\
\hline
\end{tabular}

${ }^{*}$ In each set, concrete was batched with the same sample of cement.

†Percentage by volume.

¥ Grade 120 slag cement sample number.

${ }^{\S}$ Grade 100 slag cement sample number.

Coarse aggregate: LS is limestone; $\mathrm{G}$ is granite; and Q is quartzite.

Note: $1 \mathrm{lb} / \mathrm{yd}^{3}=0.5933 \mathrm{~kg} / \mathrm{m}^{3}$.

demolded $24 \pm 1$ hour after casting and when the specimens were first subjected to drying. The specimens were dried at $73^{\circ} \pm 3^{\circ} \mathrm{F}\left(23^{\circ} \pm 2^{\circ} \mathrm{C}\right)$ and $50 \pm 4 \%$ relative humidity for 1 year. Subsequent shrinkage readings were taken every day for the first 30 days, every other day between 30 and 90 days, once a week between 90 and 180 days, and once a month between 180 and 365 days.

Companion $4 \times 8$ in. $(100 \times 200 \mathrm{~mm})$ cylinders were cast to determine compressive strength in accordance with ASTM C39/C39M (2009).

\section{EXPERIMENTAL RESULTS AND DISCUSSION Program I}

Program I was designed to compare the free shrinkage of mixtures containing various replacement levels of Grade 120 slag cement. In the first set, mixtures with volume replacements of $0,30,60$, and $80 \%$ of cement with slag cement were evaluated, and all concrete was cast with limestone coarse aggregate. The average shrinkage strains for drying periods of $0,30,90$, and 365 days and curing periods of 7 and 14 days are summarized in Table 3 . The average free shrinkage is plotted as a function of drying period for mixtures in Program I Set 1 over 30 and 365 days in Fig. 1 and 2, respectively. The mixtures are shown in the legend in the order of descending shrinkage at the end of the 30 and 365 days.

As shown in Table 3 and Fig. 1, the use of Grade 120 slag cement as a partial replacement of cement reduces early-age shrinkage. For the Grade 120 slag cement sample (I), at 30 days, the $30 \%$ slag (I) mixture that cured for 7 days exhibited about the same shrinkage as the $100 \%$ cement mixture that cured for 7 days; all of the other mixtures had less shrinkage and in most cases considerably less shrinkage than the corresponding $100 \%$ cement mixture. For specimens cured for 14 days, the $30 \%$ slag (I) mixture had $50 \mu \varepsilon$ less shrinkage than the $100 \%$ cement mixture, increasing to $100 \mu \varepsilon$ when the slag cement content was increased to $60 \%$. A second sample of Grade 120 slag cement (II) at replacement levels of 60 and $80 \%$ by volume was also examined in this set of specimens. As shown in Table 3 and Fig. 1, the 60\% slag (II) mixtures still had significantly less shrinkage than the $100 \%$ cement mixtures, and a further reduction in shrinkage was observed as the content of slag cement (II) was increased to $80 \%$. At 30 days, the $80 \%$ slag (II) mixture only had shrinkage of 
Table 3-Average free shrinkage, $\mu \varepsilon^{\star}$

\begin{tabular}{|c|c|c|c|c|c|c|c|c|c|c|c|c|c|c|c|c|c|c|c|c|}
\hline \multirow{4}{*}{$\begin{array}{l}\text { Drying } \\
\text { period, } \mathrm{d}\end{array}$} & \multicolumn{10}{|c|}{ Program I Set 1} & \multicolumn{10}{|c|}{ Program I Set 2} \\
\hline & \multicolumn{2}{|c|}{$\begin{array}{c}100 \% \text { cement } \\
\text { LS }\end{array}$} & \multicolumn{2}{|c|}{$\begin{array}{l}30 \% \text { slag } \\
\text { (I), LS }\end{array}$} & \multicolumn{2}{|c|}{$\begin{array}{l}60 \% \text { slag } \\
\text { (I), LS }\end{array}$} & \multicolumn{2}{|c|}{$\begin{array}{c}60 \% \text { slag (II), } \\
\text { LS }\end{array}$} & \multicolumn{2}{|c|}{$\begin{array}{c}80 \% \text { slag (II), } \\
\text { LS }\end{array}$} & \multicolumn{5}{|c|}{$100 \%$ cement, $\mathrm{G}$} & \multicolumn{5}{|c|}{$60 \%$ slag (II), G } \\
\hline & \multicolumn{20}{|c|}{ Curing period, $\mathrm{d}$} \\
\hline & 7 & 14 & 7 & 14 & 7 & 14 & 7 & 14 & 7 & 14 & 3 & 7 & & 14 & 28 & 3 & 7 & & & 28 \\
\hline 0 & -43 & -33 & -40 & -20 & -47 & -47 & -57 & -57 & -63 & -80 & -23 & -5 & & -43 & -37 & -85 & -77 & -1 & & -103 \\
\hline 30 & 320 & 283 & 317 & 233 & 280 & 183 & 193 & 163 & 73 & 47 & 358 & 34 & & 277 & 264 & 280 & 254 & & & 160 \\
\hline 90 & 413 & 387 & 407 & 353 & 383 & 337 & 323 & 320 & 283 & 227 & 438 & 41 & & 364 & 341 & 332 & 320 & & & 239 \\
\hline 365 & 483 & 460 & 507 & 443 & 477 & 433 & 413 & 393 & 390 & 383 & 482 & 43 & & 392 & 363 & 368 & 365 & & & 313 \\
\hline \multirow{4}{*}{$\begin{array}{l}\text { Drying } \\
\text { period, } d\end{array}$} & \multicolumn{10}{|c|}{ Program II Set 1} & \multicolumn{10}{|c|}{ Program II Set 2} \\
\hline & \multicolumn{3}{|c|}{$100 \%$ cement, LS } & \multicolumn{4}{|c|}{$30 \%$ slag (i), LS } & \multicolumn{3}{|c|}{$60 \%$ slag (i), LS } & \multicolumn{4}{|c|}{$100 \%$ cement, G } & \multicolumn{2}{|c|}{$\begin{array}{c}30 \% \text { slag } \\
\text { (ii), G }\end{array}$} & \multicolumn{4}{|c|}{$60 \%$ slag (ii), G } \\
\hline & \multicolumn{20}{|c|}{ Curing period, $\mathrm{d}$} \\
\hline & 7 & & 14 & & 7 & 14 & & 7 & & 14 & 7 & & & 14 & 7 & 14 & & 7 & & 14 \\
\hline 0 & -53 & & -47 & & -93 & -63 & & -80 & & 143 & -63 & & & 57 & -60 & -67 & & -113 & & -107 \\
\hline 30 & 317 & & 327 & & 280 & 120 & & 200 & & 87 & 277 & & & 60 & 303 & 230 & & 287 & & 190 \\
\hline 90 & 423 & & 430 & & 367 & 323 & & 320 & & 233 & 347 & & & 23 & 333 & 303 & & 317 & & 263 \\
\hline \multirow[t]{3}{*}{365} & 457 & & 463 & & 400 & 377 & & 377 & & 17 & 430 & & & 20 & 403 & 377 & & 383 & & 347 \\
\hline & \multicolumn{10}{|c|}{ Program III Set 1} & \multicolumn{10}{|c|}{ Program III Set 2} \\
\hline & $100 \%$ & cement & LS & & & & & $60 \%$ & lag (iii & & & $\%$ & ag & (II), LS & & & $60 \%$ & o slag & I), Q & \\
\hline \multirow{2}{*}{$\begin{array}{l}\text { Drying } \\
\text { period, d }\end{array}$} & \multicolumn{20}{|c|}{ Curing period, $\mathrm{d}$} \\
\hline & - & & 14 & & - & 14 & & - & & 14 & 7 & & & 14 & & 7 & & & 14 & \\
\hline 0 & - & & -17 & & - & -77 & & - & & 43 & -5 & & & -5 & & -6 & & & -53 & \\
\hline 30 & - & & 317 & & - & 87 & & - & & 67 & 19 & & & 16 & & $30^{\circ}$ & & & 247 & \\
\hline 90 & - & & 410 & & - & 273 & & - & & 60 & 32 & & & 32 & & 39 & & & 333 & \\
\hline 365 & - & & 443 & & - & 340 & & - & & 90 & 41 & & & 39 & & 42 & & & 377 & \\
\hline
\end{tabular}

*Values are based on lengths measured upon removal from molds $24 \pm 1$ hour after casting.

Negative values indicate swelling.

73 and $47 \mu \varepsilon$ for specimens cured for 7 and 14 days, compared with 193 and $163 \mu \varepsilon$ for the $60 \%$ slag (II) mixture and 320 and $283 \mu \varepsilon$ for the $100 \%$ cement mixture cured for 7 and 14 days, respectively. For the same mixture, the specimens cured for 14 days consistently had less shrinkage than the specimens cured for 7 days.

The trend observed after 30 days of drying can also be observed after 365 days (Table 3 and Fig. 2): increasing the content of Grade 120 slag cement and increasing the curing period from 7 to 14 days results in lower shrinkage. The only exception at 365 days is the $30 \%$ slag (I) mixture that cured for 7 days, which had slightly higher shrinkage, by $24 \mu \varepsilon$, than the $100 \%$ cement concrete that cured for 7 days.

In Program I Set 2, granite was used as the coarse aggregate with a $60 \%$ volume replacement of portland cement with Grade 120 slag cement (II). The effect of curing was further evaluated in this set with specimens cured for 3, 7, 14 , and 28 days. The average shrinkage strains are presented in Table 3 and Fig. 3 and 4.

At 30 days, an increase in the curing period from 3 all the way up to 28 days consistently reduced shrinkage for both the $100 \%$ cement mixture and the $60 \%$ slag (II) mixture.
The reduction obtained by increasing the curing period from 7 to 14 days is more notable than the reduction obtained by increasing the curing period from 3 to 7 days or from 14 to 28 days. Again, the $60 \%$ slag mixtures exhibited less shrinkage than the corresponding $100 \%$ cement mixtures, with reductions of $78,88,86$, and $104 \mu \varepsilon$ for specimens cured for $3,7,14$, and 28 days, respectively.

At 365 days, the $60 \%$ slag (II) mixtures continued to exhibit less shrinkage than the $100 \%$ cement mixtures. The $60 \%$ slag (II) mixtures cured for 3 and 7 days had nearly identical shrinkage (368 and $365 \mu \varepsilon$, respectively) to the $100 \%$ cement mixture cured for 28 days $(363 \mu \varepsilon)$, and the $60 \%$ slag (II) mixtures cured for 14 and 28 days had the least shrinkage (305 and $313 \mu \varepsilon$, respectively). Compared to the $60 \%$ slag (II) mixtures in Program I Set 1 , which contained the (more porous) limestone coarse aggregate and a paste content of $23.3 \%$, the $60 \%$ slag (II) mixtures in Set 2, with the low-absorption granite coarse aggregate and a paste content of $24.1 \%$, exhibited more shrinkage through 30 days and less shrinkage at 90 through 365 days for comparative curing periods ( 7 and 14 days). 


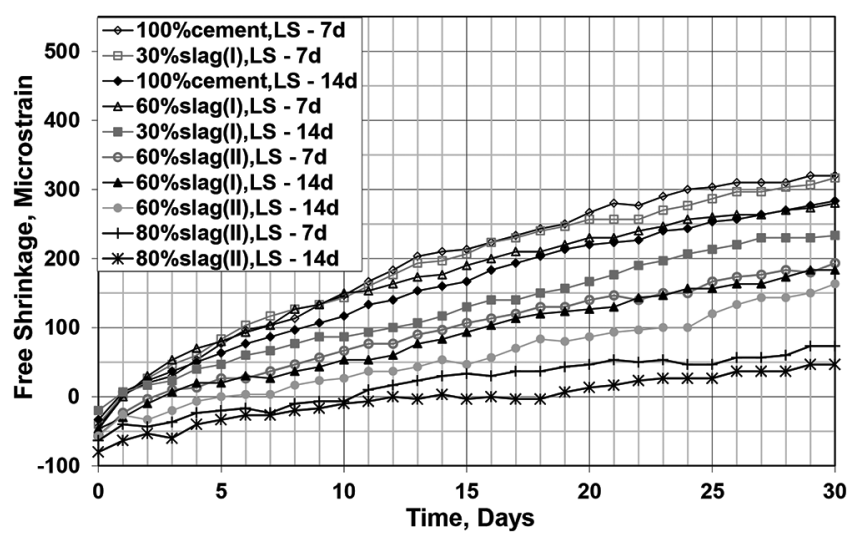

Fig. 1-Free shrinkage versus drying time through 30 days for concrete in Program I Set 1: limestone and Grade 120 slag cement (I) and (II).

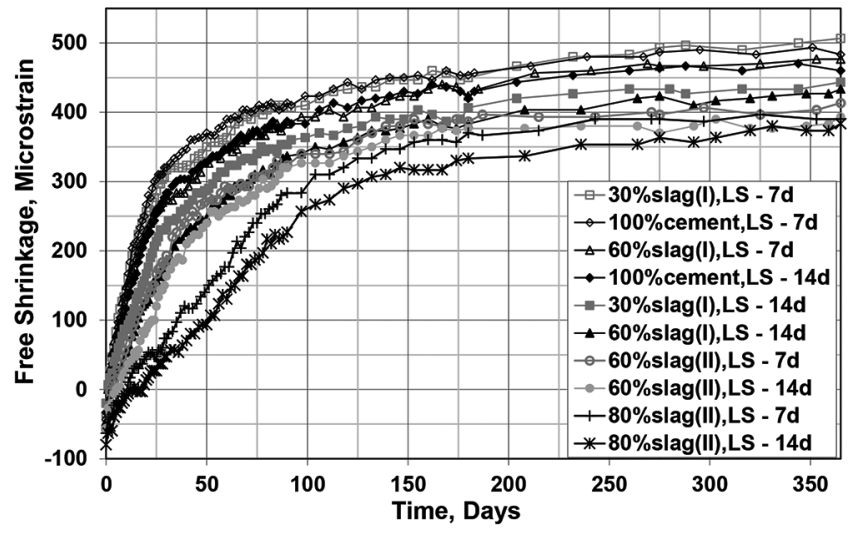

Fig. 2-Free shrinkage versus drying time through 365 days for concrete in Program I Set 1: limestone and Grade 120 slag cement (I) and (II).

\section{Program II}

The significant reductions in shrinkage observed for mixtures containing Grade 120 slag cement in Program I prompted an additional comparison of mixtures containing Grade 100 slag cement. The mixtures containing limestone coarse aggregate and replacement levels of 0,30 , and $60 \%$ (by volume) of cement with Grade 100 slag cement sample (i) were evaluated first, followed by mixtures containing granite coarse aggregate and 0,30, and 60\% volume replacements of cement with Grade 100 slag cement (ii).

The average shrinkage values for mixtures containing limestone and 0,30, and 60\% of Grade 100 slag cement (i) are presented in Table 3 and Fig. 5 and 6. At 30 days, the $60 \%$ slag (i) mixture cured for 14 days exhibited the lowest average shrinkage, $87 \mu \varepsilon$, while the $100 \%$ cement mixture cured for 7 and 14 days had the highest shrinkage, with values of 317 and $327 \mu \varepsilon$, respectively. Similar to the trend observed for mixtures cast with Grade 120 slag cement in Program I, a partial replacement of cement with Grade 100 slag cement consistently reduced shrinkage. The reduction in shrinkage increased as the slag cement content increased.

At 365 days (shown in Fig. 6), the 100\% cement mixtures cured for 7 and 14 days continued to have the highest free shrinkage, followed by the $30 \%$ slag (i) mixture cured for

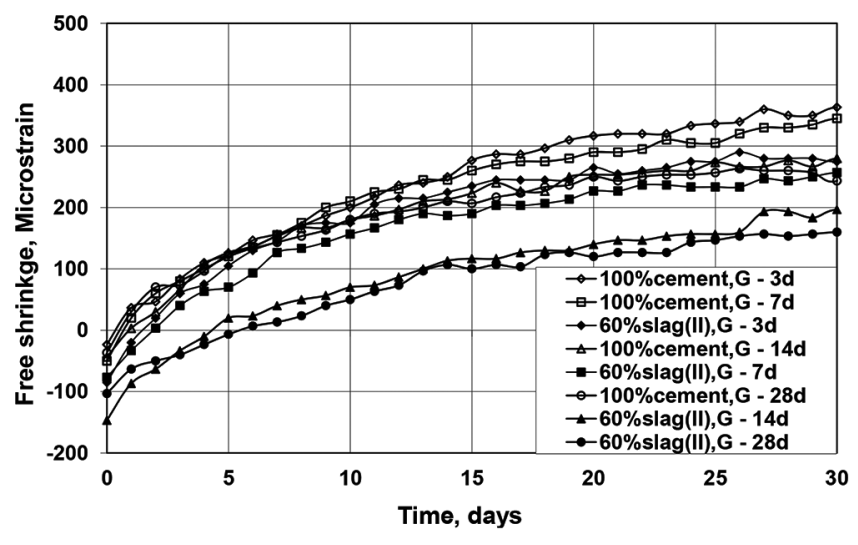

Fig. 3-Free shrinkage versus drying time through 30 days for concrete in Program I Set 2: granite and Grade 120 slag cement (II).

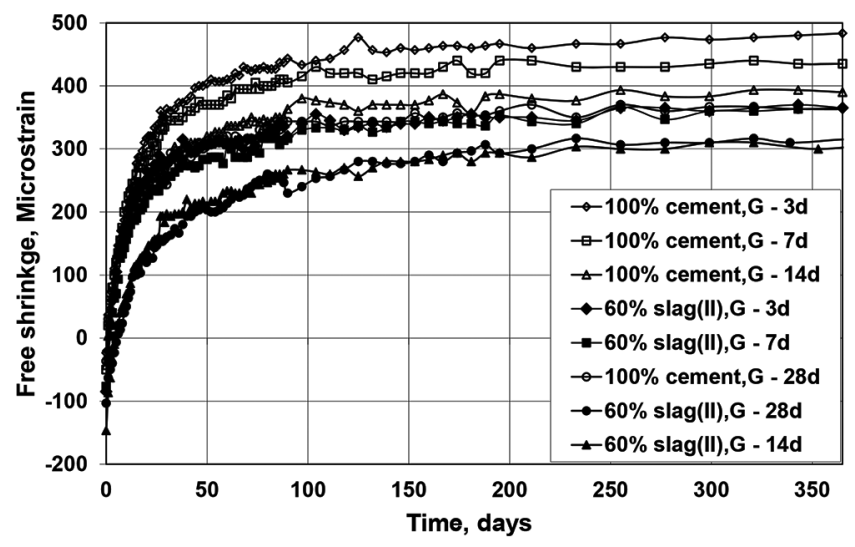

Fig. 4-Free shrinkage versus drying time through 365 days for concrete in Program I Set 2: granite and Grade 120 slag cement (II).

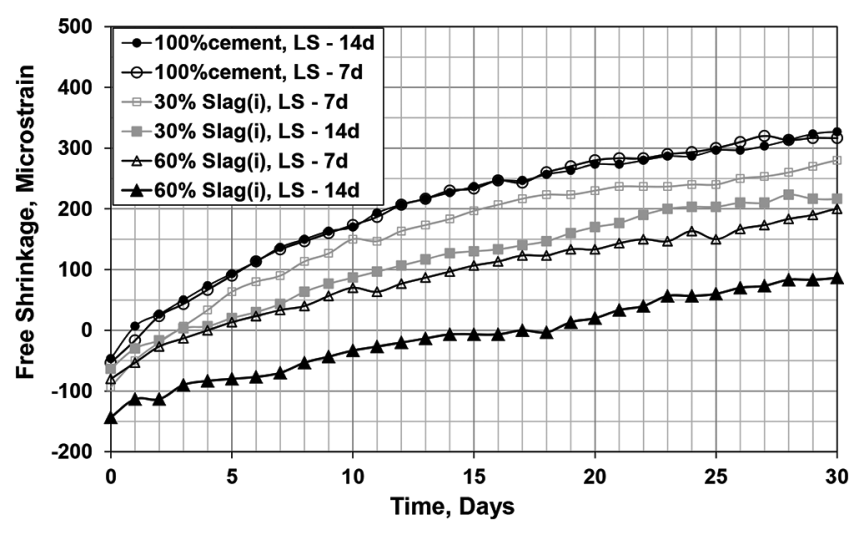

Fig. 5-Free shrinkage versus drying time through 30 days for concrete in Program II Set 1: limestone and Grade 100 slag cement (i).

7 days, the $30 \%$ slag (i) mixture cured for 14 days, the $60 \%$ slag (i) mixture cured for 7 days and the $60 \%$ slag (i) mixture cured for 14 days.

Program II Set 2 evaluated mixtures containing granite coarse aggregate and 0,30, and 60\% volume replacements of cement with Grade 100 slag cement (ii). The average shrinkage values of these mixtures are shown in Table 3 and Fig. 7 and 8 . 


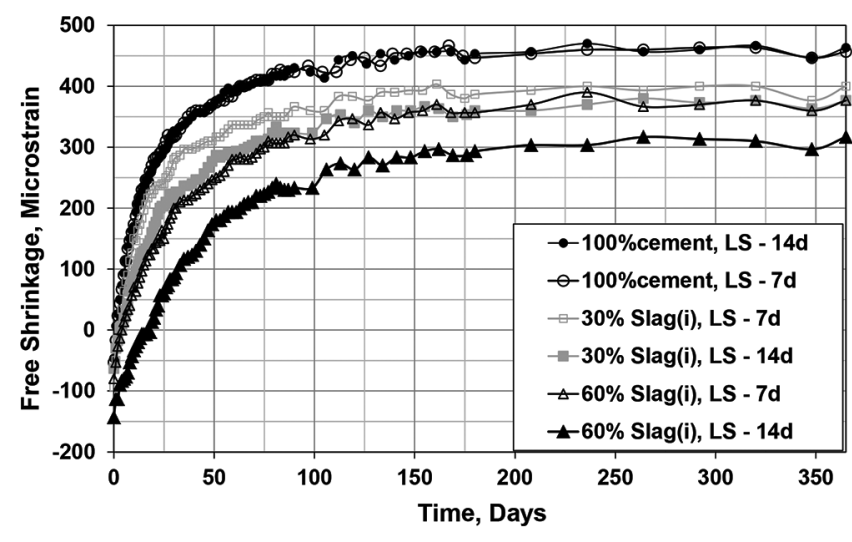

Fig. 6-Free shrinkage versus drying time through 365 days for concrete in Program II Set 1: limestone and Grade 100 slag cement (i).

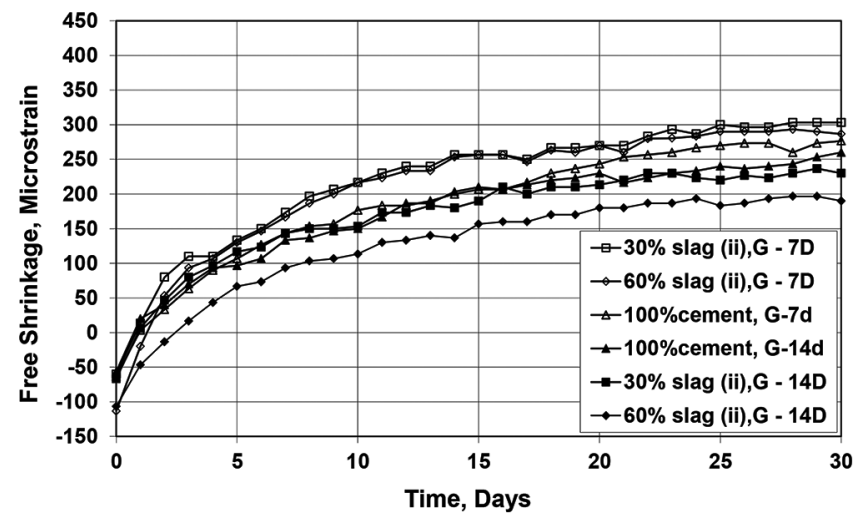

Fig. 7-Free shrinkage versus drying time through 30 days for concrete in Program II Set 2: granite and Grade 100 slag cement (ii).

As shown in Table 3 and Fig. 7, at 30 days, both the 30 and $60 \%$ slag (ii) mixtures cured for 7 days exhibited more shrinkage than the $100 \%$ cement mixture cured for 7 days. It should be noted that these are the only two slag mixtures in this study that exhibited higher shrinkage than the $100 \%$ cement mixtures at 30 days and clearly highlights the importance of longer curing for mixtures containing slag cement. This observation is evaluated further in Program III. The 30 and $60 \%$ slag (ii) mixtures cured for 14 days exhibited less shrinkage, with 30 and $70 \mu \varepsilon$ less, respectively, than the $100 \%$ cement mixture cured for 14 days.

At 365 days (Table 3 and Fig. 8), the $60 \%$ slag (ii) mixture cured for 14 days continued to have the least shrinkage, followed by the $30 \%$ slag (ii) mixture cured for 14 days, and the shrinkage of the 30 and $60 \%$ slag (ii) mixtures cured for 7 days dropped below the $100 \%$ cement mixture cured for 7 days.

\section{Program III}

Programs I and II demonstrate that increasing the curing period decreases the shrinkage of concrete mixtures. In addition to the length of the curing period, water stored in the aggregate pores is expected to provide additional curing for concrete - this effect is more pronounced for concrete containing a porous coarse aggregate (in this case, highabsorption limestone). The combined effect of using porous

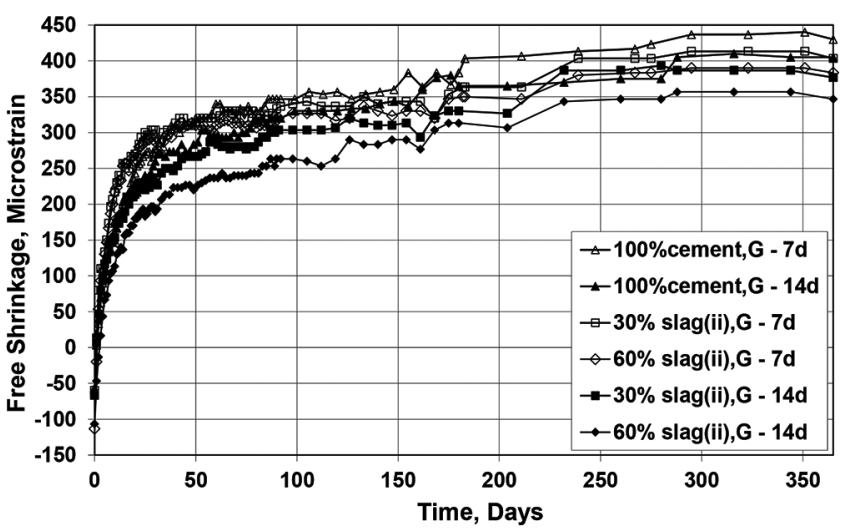

Fig. 8-Free shrinkage versus drying time through 365 days for concrete in Program II Set 2: granite and Grade 100 slag cement (ii).

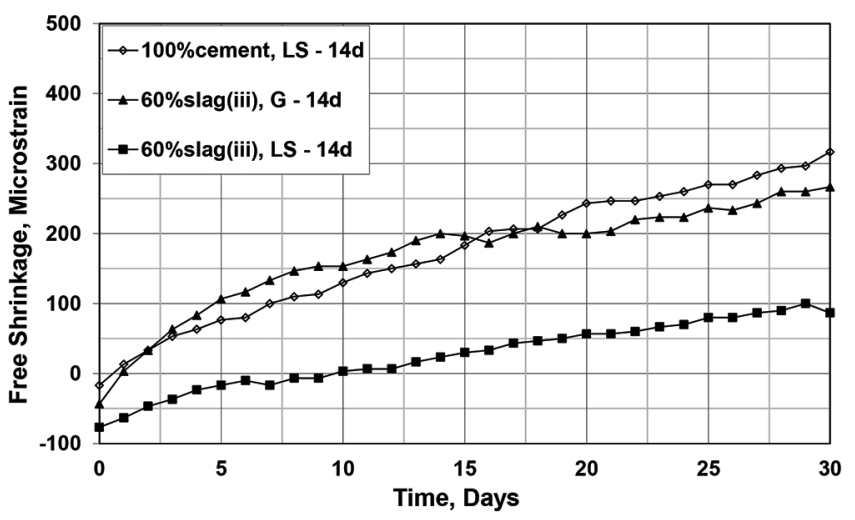

Fig. 9-Free shrinkage versus drying time through 30 days for concrete in Program III Set 1: Grade 100 slag cement (iii).

limestone coarse aggregate (with an absorption over 2.5\%) and slag cement is investigated in Program III by comparing the shrinkage of slag mixtures cast with limestone coarse aggregate with the shrinkage of slag mixtures containing granite (with an absorption of $0.6 \%$ ) (Set 1) or quartzite (with an absorption of $0.4 \%$ ) (Set 2).

In the first set, mixtures with $100 \%$ cement and mixtures containing a $60 \%$ volume replacement of cement with Grade 100 slag cement (iii) with limestone coarse aggregate, and mixtures containing a $60 \%$ volume replacement of cement with Grade 100 slag cement (iii) and granite coarse aggregate were compared. All mixtures were cured for 14 days. The free shrinkage results are shown in Table 3 and Fig. 9 and 10.

As indicated in Fig. 9, the $60 \%$ slag (iii) mixture cast with granite aggregate exhibited slightly more shrinkage than the $100 \%$ cement mixture cast with limestone aggregate for the first 15 days, and both mixtures shrank more than the $60 \%$ slag (iii) mixture cast with limestone at the same age. At 30 days, both slag mixtures had less shrinkage than the $100 \%$ cement mixture cast with limestone, and the $60 \%$ slag (iii) mixture cast with limestone aggregate exhibited $180 \mu \varepsilon$ less shrinkage than the $60 \%$ slag (iii) mixture cast with granite aggregate. At 365 days, the $60 \%$ slag (iii) mixture cast with limestone aggregate continued to exhibit the lowest shrinkage, followed by the $60 \%$ slag (iii) mixture cast with granite aggregate, and the $100 \%$ cement mixture 


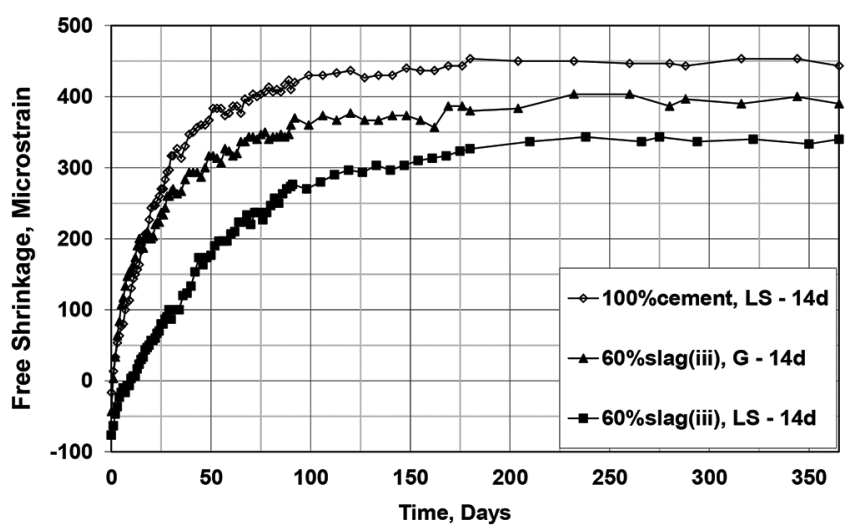

Fig. 10-Free shrinkage versus drying time through 365 days for concrete in Program III Set 1: Grade 100 slag cement (iii).

cast with limestone aggregate, with respective shrinkage strains of 340,390 , and $443 \mu \varepsilon$.

Slag mixtures cast with limestone were compared with slag mixtures cast with quartzite in Program III Set 2. Grade 120 slag (II) cement was used, and the concrete was cured for 7 or 14 days. The results are shown in Table 3 and Fig. 11 and 12. At 30 days, the slag (II) mixtures cast with limestone coarse aggregate had less shrinkage than the slag (II) mixtures cast with quartzite for concrete cured for both 7 and 14 days. The order of descending shrinkage is different after 365 days, as shown in Fig. 12. The quartzite slag mixture cured for 14 days had the least shrinkage, rather than the limestone slag mixture cured for 14 days. The change in order can be explained as follows. The limestone mixtures cured for 7 and 14 days continued to have less shrinkage than the quartzite mixtures cured for 14 days, until approximately 75 days when they exhibited more shrinkage. The internal curing provided by the water in the pores of the limestone coarse aggregate contributed to the reduced shrinkage through the first 75 days; afterward, the restraint provided by stiffer quartzite likely played a more dominant role. Browning et al. (2011) further investigated the effect of internal curing provided by porous limestone or lightweight fine aggregate (compared to mixtures cast with a low absorption coarse aggregate) and found that reductions in shrinkage were greater for mixtures containing slag as a partial replacement of portland cement compared to those containing $100 \%$ portland cement. Prewetted, vacuumsaturated lightweight fine aggregate was more effective than limestone in reducing shrinkage of mixtures containing slag as a partial replacement for portland cement.

Reductions in shrinkage with slag-The relative reductions in shrinkage of mixtures containing slag as a partial replacement for portland cement compared to the corresponding $100 \%$ portland cement mixtures with the same $w /$ $\mathrm{cm}$, paste content, aggregate type, and curing period at 30 , 90, and 365 days are shown in Table 4 . For the 21 batches compared in Table 4, all of the slag mixtures exhibited less shrinkage than the $100 \%$ cement mixtures, with the exception of the $30 \%$ Grade 120 slag (I) mixture in Program I cured for 7 days at 365 days and the 30 and $60 \%$ Grade 100 slag (ii) mixtures in Program II cured for 7 days at 30 days.

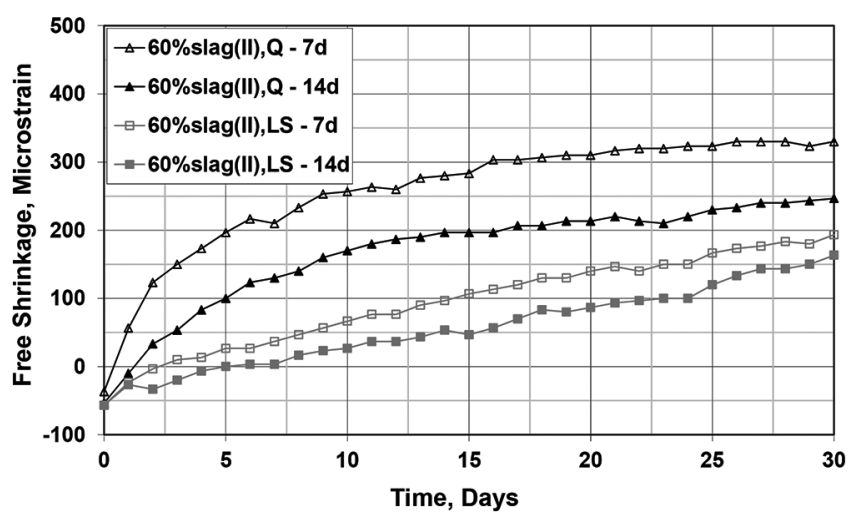

Fig. 11-Free shrinkage versus drying time through 30 days for concrete in Program III Set 2: Grade 120 slag cement (II).

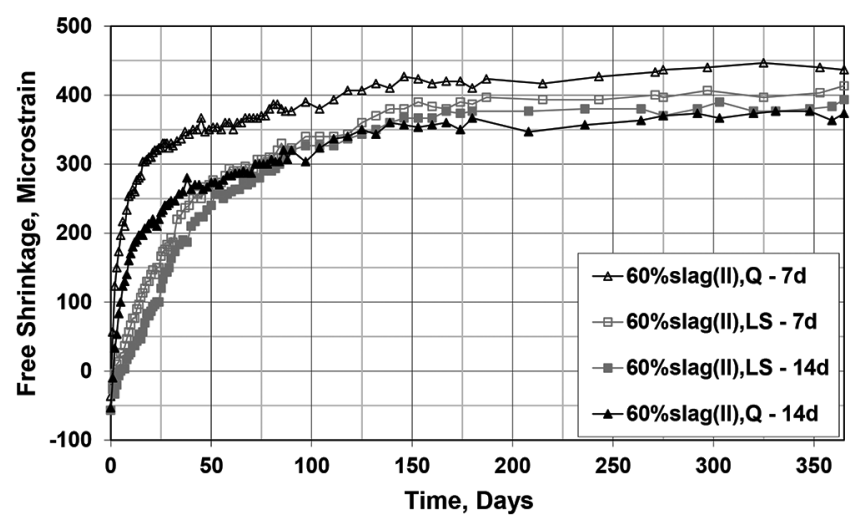

Fig. 12-Free shrinkage versus drying time through 365 days for concrete in Program III Set 2: Grade 120 slag cement (II).

For the $30 \%$ slag mixtures, the concrete cured for 7 days exhibited similar or lower shrinkage than the $100 \%$ cement mixtures. As shown in Table 4, the 30\% Grade 120 slag (I) mixture had shrinkage reductions of 1,2 , and $-5 \%$ (negative value indicating more shrinkage); the $30 \%$ Grade 100 slag (i) mixture had reductions of 12,13 , and $13 \%$; and the $30 \%$ Grade 100 slag (ii) mixture had shrinkage reductions of $-9,4$, and $6 \%$ at 30,90 , and 365 days, respectively. When the curing period was increased to 14 days, the reduction in shrinkage was significant for all the $30 \%$ slag mixtures. The reductions for the three $30 \%$ slag mixtures ranged from 12 to $34 \%$ with an average of $21 \%$ (compared to an average of $1 \%$ for concrete cured for 7 days) at 30 days and from 4 to $19 \%$ with an average of $11 \%$ (compared to the average of $5 \%$ for concrete cured to 7 days) at 365 days.

For the $60 \%$ slag mixtures, concrete cured for both 7 and 14 days had considerably less shrinkage than the $100 \%$ cement mixtures, as shown in Table 4, except for the $60 \%$ Grade 100 slag (ii) mixture cured for 7 days at 30 days. On average, the $60 \%$ mixtures had 22 and $35 \%$ less shrinkage at 30 days and 12 and 19\% less shrinkage at 365 days for specimens cured for 7 and 14 days, respectively.

One $80 \%$ slag mixture was included in this study. The reductions were significant at 30 days, with values that were 77 and $83 \%$ lower than obtained with the $100 \%$ cement mixtures for specimens cured for 7 and 14 days, respectively. 
Table 4-Summary of shrinkage reductions of slag mixtures compared to $100 \%$ portland cement mixtures

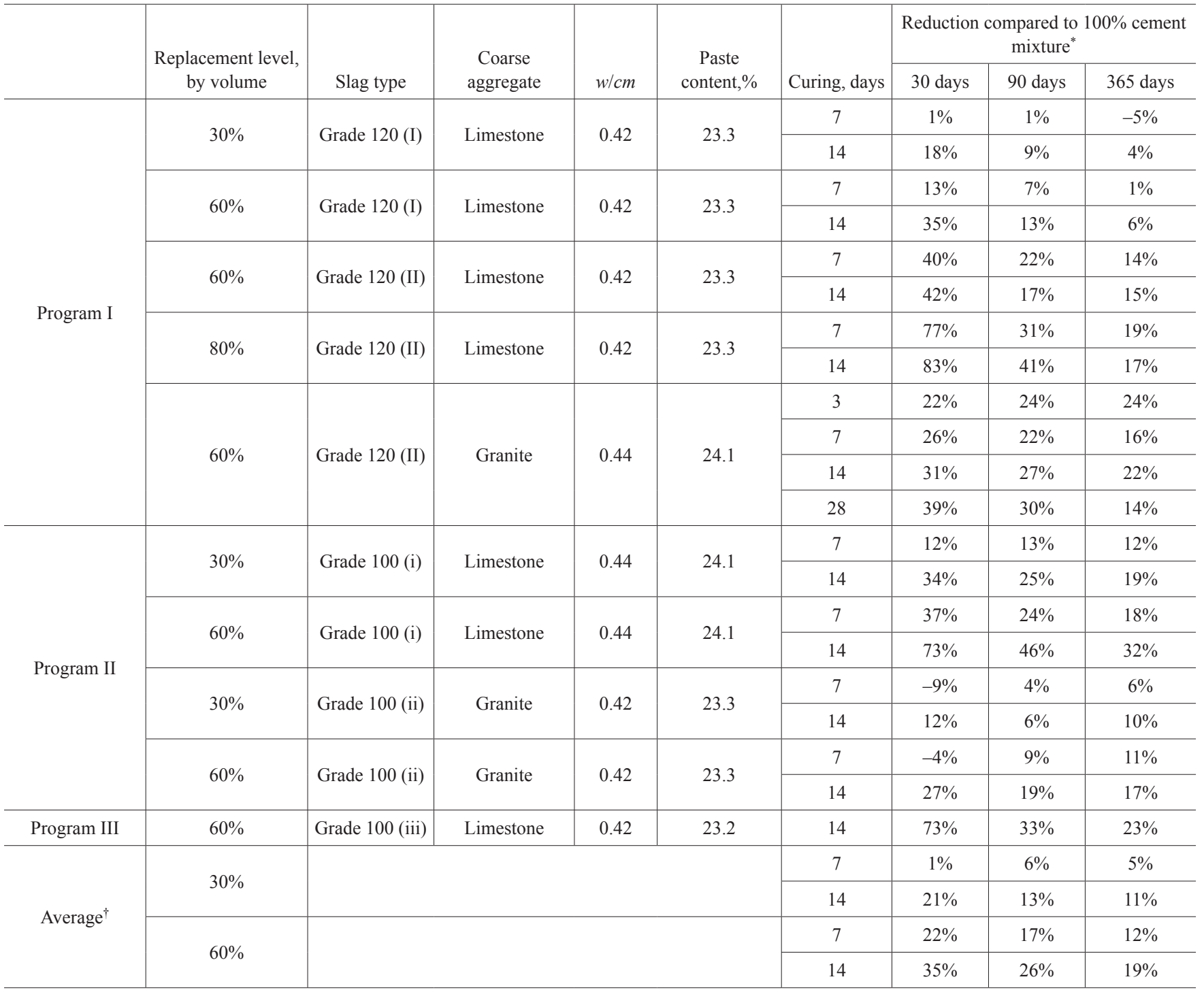

"Negative values indicate the slag mixtures shrank more than the $100 \%$ cement mixtures.

${ }^{\dagger}$ The average of the mixtures containing the same replacement level of slag cement, regardless of the slag type and aggregate type.

The reductions were 19 and $17 \%$ at 365 days for specimens cured for 7 and 14 days, respectively.

The reductions observed at 365 days resulting from adding slag cement and from increasing the curing period from 7 to 14 days decrease compared to the reductions observed after 30 days. For example, at 30 days, the $80 \%$ slag (II) mixture only had a shrinkage of $47 \mu \varepsilon$ for specimens cured for 14 days, and the reduction was $236 \mu \varepsilon$ compared to the $100 \%$ cement mixture cured for 14 days ( $283 \mu \varepsilon$ at 30 days); at 365 days, the reduction decreased to $77 \mu \varepsilon$ ( $460 \mu \varepsilon$ for the $100 \%$ cement mixture compared to $383 \mu \varepsilon$ for the $80 \%$ slag [II] mixture). When the reductions at 30 and 365 days are compared across all programs, 30 of the 37 comparisons in the study follow the same trend with higher reductions in shrinkage at early ages that decrease over time. Greater reductions at early ages are important, however, because they reduce stresses caused by restrained shrinkage that occur before the concrete has time to creep and relieve those stresses.

It is also important to note that the specimens in each program exhibited various levels of swelling (negative shrinkage) during the curing period. Swelling occurring in concrete that is restrained, such as bridge decks, is beneficial due to the compression that results. The amount of swelling increases with the addition of slag, as shown in Fig. 1 through 12 and Table 4. For each curing period (3, 7, 14, or 28 days), the addition of slag cement increased swelling compared to the $100 \%$ portland cement mixture for 20 out of the 24 comparisons. Browning et al. (2011) found that increasing the curing period from 7 to 14 days also tends to increase swelling, although this was not observed in this study. Of the 15 mixtures cured for both 7 and 14 days, increasing the curing period resulted in lower swelling for nine mixtures, higher swelling for three mixtures, and no change for the remaining three. To discount differences due to swelling, the mixtures in Programs I, II, and III are compared in Fig. 13, 14, and 15, respectively, by plotting average values of drying shrinkage based on total length change following the curing period at 30 and 365 days. In addition to the average values of free shrinkage, the figures also show the maximum and minimum values for the three specimens used 


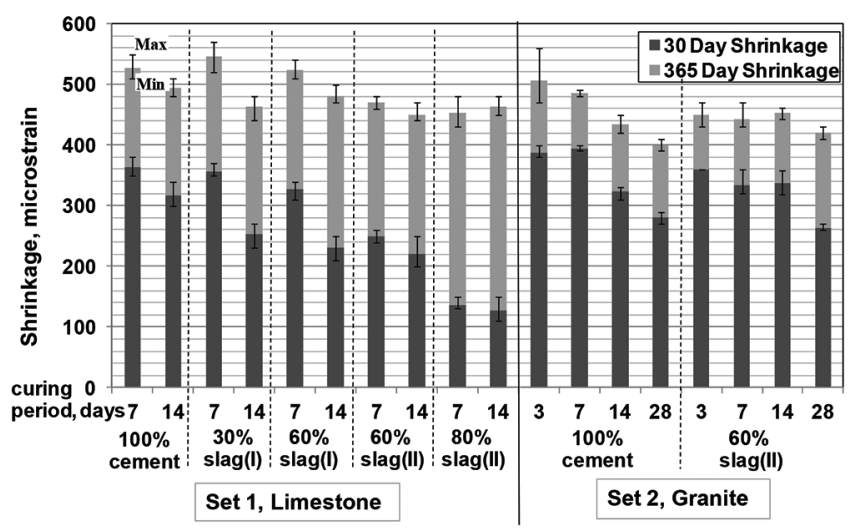

Fig. 13-Free shrinkage at 30 and 365 days based on total length change after curing for mixtures in Program I.

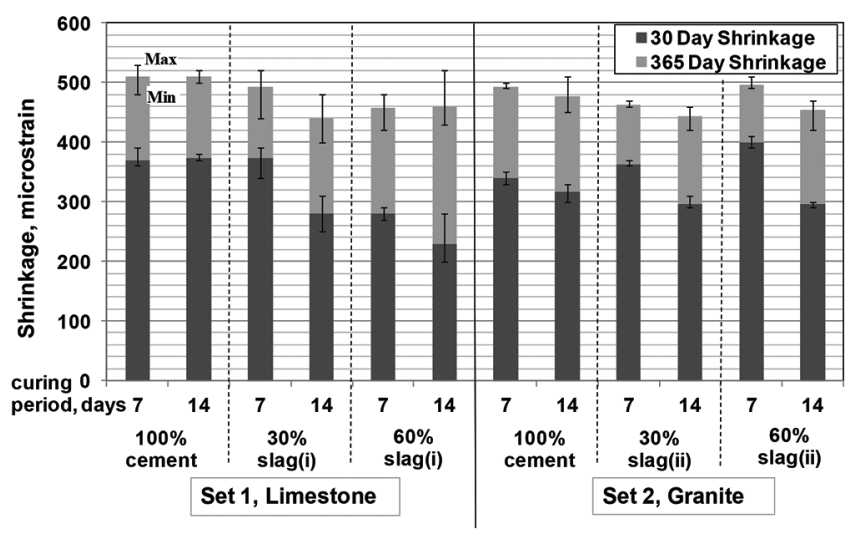

Fig. 14-Free shrinkage at 30 and 365 days based on total length change after curing for mixtures in Program II.

for each parameter. These figures illustrate that with only a few exceptions, the trends observed previously that show a reduction in shrinkage with the addition of slag cement and longer curing are maintained for up to 1 year of drying (although the trends are somewhat less pronounced), independent of swelling.

Compressive strength-The compressive strengths of all the mixtures in this study are presented in Fig. 16. The mixtures in each set had the same $w / \mathrm{cm}$ and paste content. As shown in Fig. 16, the mixtures containing Grade 120 slag had higher compressive strengths, at both 7 and 28 days, than the corresponding $100 \%$ cement mixtures. All mixtures containing Grade 100 slag exhibited lower 7-day compressive strengths, in the range of 530 to 1330 psi (3.7 to 9.2 $\mathrm{MPa}$ ) lower, than the $100 \%$ cement mixtures, with only one exception (the $30 \%$ slag (ii) mixture had a higher 7-day compressive strength in Program II Set 2). The 28-day relative compressive strengths of Grade 100 slag mixtures were mixed, with some having higher and some having lower compressive strength than the corresponding $100 \%$ cement mixtures. The relative strengths of the mixtures are not unexpected considering the relative activities of the two slag grades (ASTM C989/C989M 2012).

\section{SUMMARY AND CONCLUSIONS}

The effect of a partial replacement of cement with either Grade 120 and Grade 100 slag cement on free shrinkage

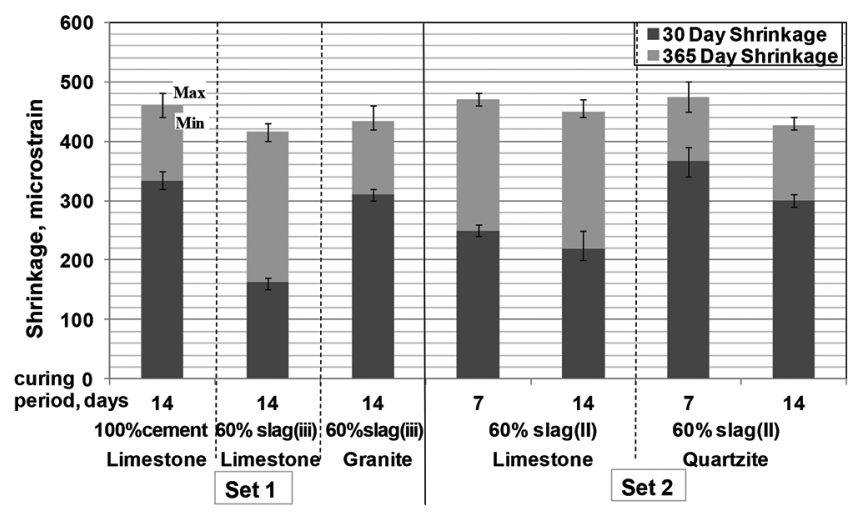

Fig. 15-Free shrinkage at 30 and 365 days based on total length change after curing for mixtures in Program III.

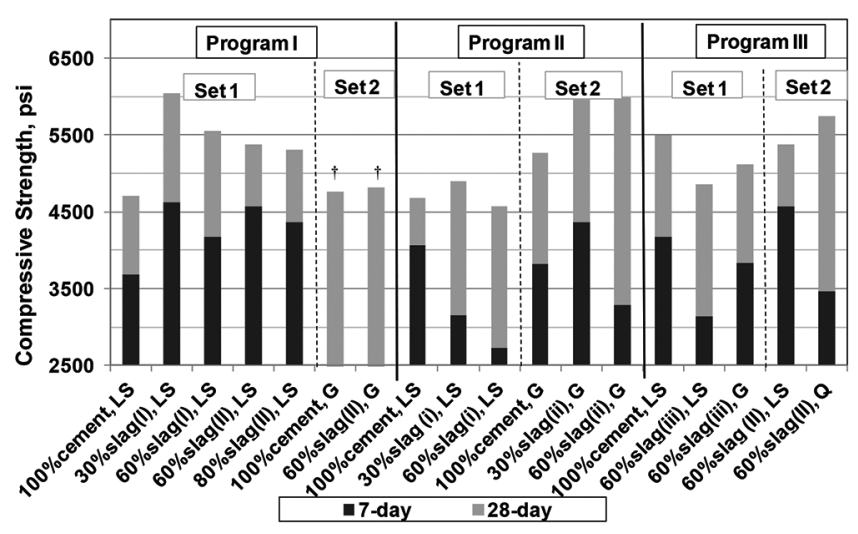

Fig. 16-Compressive strength. Dagger ( $\dagger$ indicates 7-day compressive strength was not obtained. (Note: 1000 psi = 6.89 MPa.)

was evaluated in this study. Mixtures included concretes containing different replacement levels of slag cement (30, 60 , and $80 \%$ by volume) cast with limestone, granite, or quartzite coarse aggregate. Comparisons are only made with mixtures having the same $w / \mathrm{cm}$, paste content (by volume), and sample of cement. Mixtures were cast with concrete with a slump of $3 \pm 1 \mathrm{in}$. (75 $\pm 25 \mathrm{~mm})$ and an air content of $8.4 \pm 0.5 \%$ at a concrete temperature of $70 \pm 3^{\circ} \mathrm{F}(21.1 \pm$ $\left.1.7^{\circ} \mathrm{C}\right)$.

The following conclusions are based on the results and analysis presented in this paper.

1. Increasing the curing period decreases free shrinkage.

2. In general, for constant paste content, a partial replacement of portland cement with slag cement decreases free shrinkage compared to mixtures containing $100 \%$ portland cement. The greatest reductions were generally observed at early ages, and the reductions increased as the replacement level of cement with slag cement increased.

3. Mixtures containing a 30\% volume replacement of cement with slag cement and cured for 7 days exhibited similar, if not less, free shrinkage than the companion $100 \%$ cement mixture cured for 7 days; when the curing period was extended to 14 days, the $30 \%$ slag mixture exhibited considerably less shrinkage. On average, shrinkage was $21 \%$ less at 30 days and $11 \%$ less at 365 days compared to the $100 \%$ portland cement mixture for concrete cured for 14 days. 
4. Mixtures containing a $60 \%$ volume replacement of cement with slag cement exhibited reductions in shrinkage, on average, of 22 and $35 \%$ at 30 days and 12 and $19 \%$ at 365 days compared to the companion $100 \%$ cement mixtures for specimens cured for 7 and 14 days, respectively.

5 . When slag cement is used in conjunction with porous limestone coarse aggregate, where internal curing is provided by water stored in the pores of the aggregate, a greater reduction in free shrinkage compared to mixtures containing $100 \%$ portland cement is observed than obtained for slag mixtures cast with a low-absorption coarse aggregate.

\section{AUTHOR BIOS}

ACI member Jiqiu Yuan is a researcher for PSI at the Turner-Fairbank Highway Research Center, Federal Highway Administration, McLean, $V A$. He received his $B S$ and $M S$ in material science and engineering from Tonji University, Shanghai, China, and the China Building Materials Academy, Beijing, China, respectively; and his PhD in civil engineering from the University of Kansas, Lawrence, KS, in 2011. He is a member of ACI Subcommittee 228-B, Visual Inspection; Committee 239, Ultra-High Performance Concrete; and Joint ACI-ASCE Committee 408, Bond and Development of Steel Reinforcement.

ACI member Will Lindquist is an Assistant Professor at Saint Louis University, St. Louis, MO. He received his BS, MS, and PhD in civil engineering from the University of Kansas in 2002, 2005, and 2008, respectively. He is a member of ACI Committees 308, Curing Concrete, and S802, Teaching Methods and Educational Materials.

David Darwin, FACI, is the Deane E. Ackers Distinguished Professor and Chair of the Department of Civil, Environmental and Architectural Engineering at the University of Kansas and a Past President of ACI. He is a member of ACI Committees 222, Corrosion of Metals in Concrete; 224, Cracking; Subcommittee 318-B, Reinforcement and Development; and Joint ACI-ASCE Committees 408, Bond and Development of Steel Reinforcement; 445, Shear and Torsion; and 446, Fracture Mechanics of Concrete.

JoAnn Browning, FACI, is the David and Jennifer Spencer Distinguished Chair and Dean of the College of Engineering at the University of Texas at San Antonio, San Antonio, TX. She is Chair of ACI Subcommittee 318-C, Safety, Serviceability, and Analysis, and member of the Technical Activities Committee and Committees 314, Simplified Design of Concrete Buildings; 318, Structural Concrete Building Code; 341, Earthquake-Resistant Concrete Bridges; 374, Performance-Based Seismic Design of Concrete Buildings; and Joint ACI-ASCE Committee 408, Bond and Development of Steel Reinforcement.

\section{ACKNOWLEDGMENTS}

Funding for this research was provided by the Kansas Department of Transportation, serving as the lead agency for the "Construction of CrackFree Bridge Decks, Phase I" and "Construction of Crack-Free Bridge Decks, Phase II" Transportation Pooled Fund Studies, Project Nos. TPF-5(051) and TPF-5(174). The Federal Highway Administration (FHWA) of the U.S. Department of Transportation (DOT), Colorado DOT, Delaware DOT, Idaho Transportation Department, Indiana DOT, Michigan DOT, Minnesota DOT, Mississippi DOT, Missouri DOT, Montana DOT, New Hampshire DOT, New York State DOT, North Dakota DOT, Ohio DOT, Oklahoma DOT, South Dakota DOT, Texas DOT, Wisconsin DOT, Wyoming DOT, Overland Park, KS, the University of Kansas Transportation Research Institute, and BASF Construction Chemicals, and the Silica Fume Association provided funding to the pooled fund. LRM Industries, BASF Construction Chemicals, Holcim US, Fordyce Concrete, Grace Construction Products, Ash Grove Cement, and Lafarge North America provided concrete materials.

\section{REFERENCES}

ASTM C39/C39M-09a, 2009, "Standard Test Method for Compressive Strength of Cylindrical Concrete Specimens," ASTM International, West Conshohocken, PA, $7 \mathrm{pp}$.

ASTM C157/C157M-08, 2008, "Standard Test Method for Length Change of Hardened Hydraulic-Cement Mortar and Concrete," ASTM International, West Conshohocken, PA, 7 pp.

ASTM C989/C989M-12a, 2012, "Standard Specification for Slag Cement for Use in Concrete and Mortars," ASTM International, West Conshohocken, PA, 8 pp.

Brooks, J. J.; Wainwright, P. J.; and Boukendakji, M., 1992, "Influence of Slag Type and Replacement Level on Strength, Elasticity, Shrinkage, and Creep of Concrete," Fly Ash, Silica Fume, Slag, and Natural Pozzolans in Concrete: Proceedings of the Fourth International Conference, SP-132, American Concrete Institute, Farmington Hills, MI, V. 2, pp. 1325-1341.

Browning, J.; Darwin, D.; Reynolds, D.; and Pendergrass, B., 2011, "Lightweight Aggregate as Internal Curing Agent to Limit Concrete Shrinkage," ACI Materials Journal, V. 108, No. 6, Nov.-Dec., pp. 638-644.

Darwin, D.; Browning, J.; and Lindquist, W. D., 2004, "Control of Cracking in Bridge Decks: Observations from the Field," Cement, Concrete and Aggregates, V. 26, No. 2, Dec., pp. 148-154. doi: 10.1520/CCA12320

Darwin, D.; Browning, J.; Lindquist, W.; McLeod, H. A. K.; Yuan, J.; Toledo, M.; and Reynolds, D., 2010, "Low-Cracking, High-Performance Concrete Bridge Decks - Case Studies Over the First 6 Years," Transportation Research Record: Journal of the Transportation Research Board, No. 2202, pp. 61-69.

Deshpande, S.; Darwin, D.; and Browning, J., 2007, "Evaluating Free Shrinkage of Concrete for Control of Cracking in Bridge Decks," $S M$ Report No. 89, University of Kansas Center for Research, Inc., Lawrence, $\mathrm{KS}, 290 \mathrm{pp}$.

Fulton, F. S., 1974, "The Properties of Portland Cement Containing Milled Granulated Blast-Furnace Slag," Monograph, Portland Cement Institute, Johannesburg, South Africa, pp. 4-46.

Hogan, F. J., and Meusel, J. W., 1981, "Evaluation for Durability and Strength Development of a Ground Granulated Blast-Furnace Slag," Cement, Concrete and Aggregates, V. 3, No. 1, pp. 40-52. doi: 10.1520/ CCA10201J

Hooton, R. D.; Stanish, K.; Angel, J. P.; and Prusinski, J., 2009, “The Effect of Ground Granulated Blast Furnace Slag (Slag Cement) on the Drying Shrinkage of Concrete-A Critical Review of the Literature," Slag Cement Concrete, SP-263, American Concrete Institute, Farmington Hills, MI, pp. 79-94.

Klieger, P., and Isberner, A. W., 1967, "Laboratory Studies of Blended Cement-Portland Blast-Furnace Slag Cements," Journal, PCA Research and Development Department Laboratories, V. 9, No. 3, Sept., pp. 2-22.

Lindquist, W.; Darwin, D.; and Browning, J., 2008, "Development and Construction of Low-Cracking High-Performance Concrete (LC-HPC) Bridge Decks: Free Shrinkage, Mixture Optimization, and Concrete Production," SM Report No. 92, University of Kansas Center for Research, Lawrence, KS, Nov., 504 pp.

Lindquist, W. D.; Darwin, D.; Browning, J.; and Miller, G. G., 2006, "Effect of Cracking on Chloride Content in Concrete Bridge Decks," $A C I$ Materials Journal, V. 103, No. 6, Nov.-Dec., pp. 467-473.

McLeod, H. A. K.; Darwin, D.; and Browning, J., 2009, "Development and Construction of Low-Cracking High-Performance Concrete (LC-HPC) Bridge Decks: Construction Methods, Specifications, and Resistance to Chloride Ion Penetration," SM Report No. 94, University of Kansas Center for Research, Lawrence, KS, Sept., 815 pp.

Tazawa, E.; Yonekura, A.; and Tanaka, S., 1989, "Drying Shrinkage and Creep of Concrete Containing Granulated Blast Furnace Slag," Fly Ash, Silica Fume, Slag, and Natural Pozzolans in Concrete: Proceedings of Third International Conference, SP-114, American Concrete Institute, Farmington Hills, MI, pp. 1325-1343.

Yuan, J.; Darwin, D.; and Browning, J., 2011, "Development and Construction of Low-Cracking High-Performance Concrete (LC-HPC) Bridge Decks: Free Shrinkage, Restrained Ring Tests, Construction Experience, and Crack Survey Results," SM Report No. 103, University of Kansas Center for Research, Lawrence, KS, Sept., 505 pp. 